\title{
O profissional atuante na preservação audiovisual
}

\author{
Ines Aisengart Menezes'
}

\begin{abstract}
Resumo
Este artigo apresenta um histórico acerca do recente desenvolvimento da área de preservação do patrimônio audiovisual brasileiro e aborda os desafios existentes, sobretudo no que concerne à profissionalização. Os profissionais que atuam na preservação do patrimônio audiovisual não contam com reconhecimento nem com regulação de sua profissão pelo Ministério do Trabalho. Não há um programa específico para formação na área e a nomenclatura da profissão ainda não conta com consenso da categoria. Este artigo evidencia a fragilidade da profissão e do patrimônio audiovisual brasileiro no momento.

\section{Palavras-chave:}

Preservação Audiovisual, Patrimônio Audiovisual, Preservacionista Audiovisual, Arquivista Audiovisual, Profissionalização.
\end{abstract}

\begin{abstract}
This article presents the recent developments of the Brazilian audiovisual heritage and addresses the existing challenges, especially regarding professionalization. The professionals who work in the preservation of the audiovisual heritage do not have recognition or regulation of their profession by the Ministry of Labor.There is no specific program for training in the area and the nomenclature of the profession still does not count on consensus by its professionals. This article highlights the fragility of the profession and the Brazilian audiovisual heritage at the moment.

\section{Keywords:}

Audiovisual Preservation, Audiovisual Heritage, Audiovisual Archivist, Audiovisual Preservationist, Professionalization.
\end{abstract}

A preservação consciente e objetiva da memória é um ato intrinsecamente político e pleno de valores. Nós somos o que acreditamos ser, o que dizemos que somos e demonstramos que somos.

Ray Edmondson, Arquivística audiovisual: filosofia e princípios, 2017.

A atividade de preservação audiovisual é relativamente nova - assim como é elementar a construção da identidade de seus profissionais, tema deste artigo. A formação, atualização e a valorização dos profissionais da área é um aspecto central para o reconhecimento do audiovisual como parte integrante do patrimônio cultural.

A área de preservação audiovisual passa por um processo de amadurecimento, com início nos anos 2000. Apesar dos avanços, há ainda muito a ser feito, por meio de construção de políticas específicas nas esferas municipais, estaduais e federais; da criação de parcerias com iniciativas privadas; da criação de programas de financiamento; do fortalecimento das instituições; da inclusão da preservação no ensino de audiovisual; da criação de formação específica para

I Ines Aisengart Menezes possui bacharelado em Comunicação Social, Habilitação Cinema, pela Universidade Federal Fluminense e mestrado em "Heritage Studies: Preservation and Presentation of the Moving Image", pela Universiteit van Amsterdam. Trabalha no setor de Preservação de Filmes da Cinemateca Brasileira desde 2016. 
a área; da integração do audiovisual nas instituições de patrimônio e museológicas no Brasil; e da consolidação do profissional atuante na área de preservação audiovisual.

Qual a denominação para a profissão daqueles que atuam na área de preservação audiovisual? Como são qualificados estes profissionais? Quem são? O objetivo deste artigo é apresentar uma abordagem técnica, considerando a minha experiência e atuação profissional na área - de forma errática desde 200I, e de modo constante desde 2014 .

Para este artigo serão utilizadas as definições do Estatuto da Associação Brasileira de Preservação Audiovisual (ABPA) para os termos obra e preservação audiovisual:

Por "obra ou registro audiovisual" se entenderá o produto da fixação ou transmissão de imagens, com ou sem som, que tenha a finalidade de criar a impressão de movimento, independentemente dos processos de captação, do suporte utilizado inicial ou posteriormente para fixá-las ou transmiti-las, ou dos meios utilizados para sua veiculação, reprodução, transmissão ou difusão.

Por "preservação audiovisual” se entenderá o conjunto dos procedimentos, princípios, técnicas e práticas necessários para a manutenção da integridade do documento audiovisual e garantia permanente da possibilidade de sua experiência intelectual (ABPA, 2012: I).

A preservação audiovisual abarca também os materiais correlatos textuais, iconográficos, objetos relacionados à obra audiovisual, contextualizando suas formas de produção e apresentação. O cinema, foco deste Dossiê, é uma manifestação cultural audiovisual cujas suas estratégias de salvaguarda possuem especificidades, contempladas em estratégias mais amplas de preservação audiovisual.

O audiovisual é uma manifestação cultural recente, em relação às demais abarcadas em instituição de guarda, como documentos textuais, cartográficos, pinturas e fotografias. Os primeiros setores de arquivos de filmes datam de pouco mais de um século. Em 1898 o cinegrafista polonês Bolesław Matuszewski publica o livreto "Une nouvelle source de l'histoire" ("Uma nova fonte histórica”), no qual apontava a relevância histórica do registro cinematográfico, e propunha a constituição de um "Depósito de Cinematografia Histórica", uma "criação que se impõe e será feita em qualquer grande cidade da Europa cedo ou tarde" (Contracampo, 200I). Na década de 1930, são criados os primeiros arquivos de filmes de âmbito nacional com o objetivo de salvaguarda do cinema, para além de sua intenção utilitarista (como biblioteca para empréstimo de cópias), como um patrimônio per se. Em 1938 foi criada a Federação Internacional de Arquivos de Filmes (FIAF). Em meio aos incêndios, desde os primórdios, devido à autocombustão do nitrato de celulose, e logo após as duas primeiras ondas de destruição ${ }^{2}$, ocasionadas pelo desenvolvimento tecnológico do próprio cinema (Costa, 2013: 19), a década de 30 do século $X X$ consiste em um marco temporal do desenvolvimento da consciência profissional no campo da preservação audiovisual, na Europa e América do Norte.

No Brasil, a iniciativa pioneira provavelmente foi a criação de um setor

2 Em 1910, a destruição de filmes curtos com o estabelecimento de longas-metragens; final da década de 1920, os filmes "silenciosos", com o advento do som na película. 
para arquivamento de filmes educativos por Edgard Roquette Pinto em 1910, a Filmoteca Científica no Museu Nacional. Contudo, segundo Carlos Roberto de Souza (2009: I5), tal evento não pode ser confirmado, o que talvez se trate de um indício da falibilidade em preservar nossa própria memória institucional. 0 mesmo autor (2009: 42) localizou o termo "cinemateca" na nota "Um Conservatorio de Films", publicada na revista "Eu Sei Tudo", em I923. A consciência da importância da preservação e da criação de uma instituição de guarda é registrada em editorial da revista "Cinearte" em 1929, sobre o então recém-criado Museu Cinematographico nos Estados Unidos, com o comentário de que esta iniciativa no Brasil seria recebida com gargalhadas (Cinearte, 1929). Pedro Lima, em 1946, "chama a atenção para a necessidade de se fundar um museu do cinema no país”, em seu artigo "O museu de Cinema” (Quental, 20 I0: 83). Em 1948, Jurandyr Noronha, em "Indicações para a organização de uma filmoteca brasileira”, artigo na revista "A Scena Muda”, refere-se ao tema, com um lamento forte pelas perdas já registradas e com indicações para a construção de uma instituição para preservação de filmes e de materiais correlatos; diretrizes para manipulação de filmes; práticas de projeção e o que depois viria a ser chamado de restauração (Noronha, 1948: 9).

No final da década de $1940^{3}$ é criada a Filmoteca do Museu de Arte Moderna de São Paulo (Filmoteca do MAM-SP), que viria a se tornar a Cinemateca Brasileira, incorporada à administração pública em 1984. Em I 955 é criada a Cinemateca do Museu de Arte Moderna do Rio de Janeiro (Cinemateca do MAM$-\mathrm{RJ}$ ). Ambas são inspiradas em Henri Langlois e a Cinémathèque française, bem como no modelo do Museum of Modern Art (MoMA), originalmente com foco na cinefilia, inicialmente do cinema mundial e, posteriormente, do cinema brasileiro. A criação da "I Mostra Retrospectiva do Cinema Brasileiro" na Filmoteca do MAM-SP em 1952 foi um marco histórico para a prospecção de materiais do cinema brasileiro, com relevante atuação de Caio Scheiby (Souza, 2009: 6I).

A criação das cinematecas em São Paulo e no então Distrito Federal ocorre no âmbito de um movimento internacional de criação de cinematecas no Leste Europeu, Ásia e América Latina, nos anos 1940, em associação ao que Hernani Heffner (200I) identifica como um processo em que o "direito à memória cinematográfica nacional passa a ser um instrumento de luta e libertação”. Em 1965 é criado o primeiro Museu de Imagem e Som. O Arquivo Nacional, criado em 1838, tem 1975 como o ano da criação da Divisão de Documentação Audiovisual.

Ao longo de décadas, estas instituições passam a abranger outros tipos de manifestações audiovisuais para além do cinema, como obras de televisão, registro doméstico, científico, publicitário, educacional e institucional, e novas modalidades de materiais correlatos. Na segunda década do século $X X I$, a produção audiovisual presente em tais arquivos e cinematecas é diversa, ainda que seus nomes permaneçam associados ao cinema e ao filme.

A Organização das Nações Unidas para a Educação, a Ciência e a Cultura (UNESCO) tem grande importância no delineamento de políticas para o patrimônio audiovisual, sobretudo com o marco "Recomendação sobre a Salvaguarda e Conservação das Imagens em Movimento" (1980), sobre o valor cultural e histórico de documentos audiovisuais, com proposições claras para sua salvaguarda ${ }^{4}$. Segundo o australiano Ray Edmondson (2017:2), um dos prin-

3 Sobre a contestação em torno da data de criação da Cinemateca Brasileira, ver Bezerra (2014: 89). 4 Além do documento de 1980, destacam-se as seguintes iniciativas da UNESCO: o Fundo UNESCO/ FIAF para salvaguarda do patrimônio fílmico (1995); o Programa Memória do Mundo; e o International 
cipais teóricos da área, na década de 1990 uma "base teórica codificada para a profissão tornou-se finalmente uma preocupação", devido ao reconhecimento do audiovisual como componente do patrimônio mundial, e uma expansão da atividade da preservação audiovisual no escopo dos arquivos tradicionais e em contextos comerciais. Nesta década há registro de variadas publicações-chave para a área, no estrangeiro.

No Brasil, a propagação de publicações acontece, sobretudo, na década de 2000, um marco de um processo de amadurecimento na área no Brasil. Segundo Laura Bezerra (20I5), este amadurecimento se deu por meio de investimentos em projetos de arquivos audiovisuais; a partir da criação da Mostra de Cinema de Ouro Preto (CineOP), que abriga o Encontro Nacional de Arquivos e Acervos Audiovisuais e seminários sobre a área; a formação da ABPA; além do citado aumento de publicações da área. É neste período que acervos audiovisuais e sua preservação começam a figurar como elementos de interesse para os demais atores da cadeia do audiovisual, além do aumento da "percepção da preservação audiovisual como área de atuação profissional” (Bezerra, 20I5: 28).

Um dos fatores centrais que contribuíram para este processo foi identificado por Laura Bezerra (20I4), como uma decorrência da atuação da Secretaria do Audiovisual (SAv) do Ministério da Cultura (MinC), durante o governo Lula. O "Programa Brasileiro de Cinema e Audiovisual: Brasil um país de todas as telas”, criado em 2003, contemplou a “'formação e memória', dentre os quatro eixos temáticos" 5 . Foram criados programas de regionalização da produção audiovisual que, na ótica da preservação, reforçam a relevância de criação e fortalecimento de arquivos regionais. No entanto, isto não ocorreu:

\begin{abstract}
A fragilidade do setor, por muito tempo desorganizado enquanto campo específico e tornado invisível enquanto parte constituinte das políticas de audiovisual, possibilitou - num momento de grandes avanços político-culturais - apenas a repetição de modelos de redistributivos ultrapassados e inadequados: o aumento de recursos destinados à Cinemateca Brasileira no período 2003-2010 ocorreu em detrimento de uma política nacional de preservação audiovisual, num governo que, paradoxalmente, investiu na descentralização das políticas culturais (Bezerra, 2015: 2) .
\end{abstract}

A descentralização, por meio de arquivos regionais, é uma das premissas da gestão do patrimônio que, além da importância em caso de sinistros, é fundamental no que concerne ao respeito à pluralidade cultural, às demandas e especificidades climáticas. A produção de obras com incentivo de recursos federais prevê o depósito de materiais na Cinemateca Brasileira, enquanto a produção regional fomentada pelo MinC prevê o depósito no Centro Técnico Audiovisual (CTAv). Ainda que a origem das obras seja de todas as regiões federais, o depósito está concentrado no eixo Rio - São Paulo. O Depósito Legal é um

Center for the Study of Preservation and Restoration of Cultural Property (ICCROM), órgão dedicado à preservação do patrimônio, a partir do qual foi construído o programa Sound and Image Collections Conservation (SOIMA) (BEZERRA, 2009).

5 Além de "formação e memória", "produção", “difusão" e "política externa".

6 A Cinemateca Brasileira passou por um período de consolidação neste período, com construção de depósitos climatizados para audiovisual e material correlato, expansão de seu laboratório fotoquímico e digital, aquisição de acervos e formação e expansão de sua equipe. Ao final de 2012 , foi iniciada uma grave crise, por motivo político-administrativo, que culminou na exoneração de seu diretor e desligamento do corpo técnico. Sobre o tema, ver relatório institucional de 2016 da Cinemateca Brasileira. 
processo burocrático que valida a realização da obra e atesta a conformidade com parâmetros técnicos estabelecidos, o que possivelmente justifica a centralização das análises para obtenção de padrão e rigor. Ainda assim, a produção local poderia ser contemplada em arquivos regionais, como modo de fomento da cultural local e do trabalho de arquivos regionais e de profissionais de todas as regiões do país. Para a produção contemporânea nato digital, o depósito em arquivos regionais é importante também como uma ação de preservação, considerando a especificidade do digital e a recomendação de arquivar cópias em espaços geográficos distanciados. Ainda, os arquivos regionais são importantes para a preservação de produções independentes, que não estão contempladas no mecanismo de Depósito Legal.

A descentralização de investimentos e o fortalecimento dos arquivos regionais têm sido objeto de reflexões na CineOP. Criada em 2005 como um "espaço privilegiado de reflexão sobre o cinema nacional" (Universo, 2005), já em sua primeira edição contou com debates em torno de "Preservação, Restauração e Memória do patrimônio cinematográfico brasileiro". Ao longo das edições, o evento tornou-se um fórum para as discussões acerca da área de preservação e o fortalecimento do conceito de audiovisual como patrimônio cultural. Para profissionais da área, passou a ser um espaço de encontro primordial, culminando na criação da ABPA em 2008. Foi, também, palco da aproximação da classe e de buscas e tentativas de diálogo com representantes do governo - sobretudo com MinC e Agência Nacional do Cinema (Ancine) - e de outros representantes do audiovisual - diretores, produtores, exibidores. A ABPA tem sido uma voz contínua e constante, ainda que com oscilações de seu timbre e volume, em prol de políticas, projetos (como tradução e publicação de importantes textos técnicos) e, em especial, pela projeção do patrimônio audiovisual em diversas esferas.

No que concerne às demais instituições de patrimônio no Brasil, destaca-se que o audiovisual não é explicitamente contemplado como Patrimônio Cultural Material pelo Instituto do Patrimônio Histórico e Artístico Nacional (Iphan), definido como:

[...] isolados ou em conjunto, os bens imóveis, os sítios urbanos, bens móveis e integrados, históricos, artísticos, arqueológicos, paleontológicos, etnográficos, ferroviários, paisagísticos e naturais, tombados ou de interesse para a preservação nacional (IPHAN, 2018).

O audiovisual pode ser aproximado a "bens históricos", pois em maior ou menor grau, todo material audiovisual possui sinais de seu contexto histórico, em termos de conteúdo, formas de produção. Entretanto, o audiovisual não é identificado como um patrimônio a ser preservado pela autarquia e também não é contemplado diretamente no Patrimônio Imaterial - e apenas uma importante ferramenta para seu registro, preservação e difusão, como é o caso de documentários, registros de história oral, entre outros.

Criado em 2009, o Instituto Brasileiro de Museus (lbram) é uma autarquia vinculada ao MinC, abrangendo a gestão dos museus federais, de maneira a eximir o Iphan desta obrigação. Em 2018, conta com 30 museus sob sua responsabilidade e gestão ${ }^{7}$.

7 Em setembro de 2018 foi tornada pública a Medida Provisória $n^{\circ} 850$, que trata da extinção do lbram e a criação da Agência Brasileira de Museus (ABRAM), um serviço social autônomo, na forma de pessoa jurídica de direito privado sem fins lucrativos. Tal medida provisória não foi aprovada como lei. 
Os museus de cinema são instituições focadas em acervos e exposições de objetos de pré-cinema, equipamento técnico, como câmeras, gravadores de áudio, mesa de animação, iluminação, de finalização de imagem e som, laboratoriais, projetores; películas cinematográficas e mídias de vídeo e digital; acervo de figurino e cenografia; documentos textuais como roteiros, documentos de divulgação e iconográficos como células de animação, fotografias, cartazes, storyboard, entre outros.

No Brasil há alguns acervos de tecnologia do audiovisual fora do alcance do público, como o da Cinemateca Brasileira - em 2018 sem catalogação nem tratamento. Uma parte do acervo da Cinemateca do MAM-RJ está acessível na exposição "Galáxia(s) do Cinema - Máquinas, Engrenagens, Movimentos ou this strange little thing called love", com previsão de encerramento em março de 2019. A Cinemateca Capitólio Petrobras e a Cinemateca de Curitiba possuem alguns equipamentos em exposição. As iniciativas individuais de Antônio Vituzzo em São Paulo, e Roque Araújo, em Cachoeira (BA), resultaram em dois significativos museus de cinema, de gestão privada. $O$ primeiro encontra-se fechado desde o falecimento deVituzzo, contando com exposições ocasionais feitas por seu filho, e o segundo segue em funcionamento em 2018, mas há notícias de dificuldades para sua manutenção, por falta de recursos. O Museu do Cinema Brasileiro em Niterói foi recentemente anunciado, mas ainda não há previsão de criação de acervo e de abertura ao público.

A importância do audiovisual como parte da memória coletiva é indubitável. Contudo, seu reconhecimento como integrante do patrimônio cultural não é pleno: não há nenhuma instituição filiada ao Ibram ou Iphan que contemple a tecnologia do audiovisual em um espaço museológico. A salvaguarda do patrimônio audiovisual encontra-se à margem das principais instâncias de patrimônio do país, sendo raras as discussões voltadas ao seu englobamento, com exceção daquelas fomentadas pela própria classe.

Em relação à nomenclatura do profissional, uma das principais referências na investigação de sua identidade é o livro "Arquivística audiovisual: filosofia e princípios” de Ray Edmondson, editado pela Unesco em 1998, cuja $3^{a}$ edição revisitada em português foi lançada em 2017. Nesta publicação, o profissional é denominado como 'arquivista audiovisual', posicionado entre os 'profissionais da memória', junto com bibliotecários e museólogos. Segundo Edmondson (2017: II), a terminologia não está associada ao estudo da Arquivologia (Archival Science, no original) de forma direta, mas à constituição das instituições de guarda de materiais audiovisuais: os arquivos de filmes. $O$ termo arquivo foi adotado em meados da década de 1950, por inspirar solidez e segurança.

Tradicionalmente, a Arquivologia definiu o documento audiovisual como “especial” e "não textual” (Silva, 2013: 8), o que implica uma posição hierárquica inferior, que negligencia a complexidade e as especificidades desta modalidade de documento. Em 199I é criado o Conselho Nacional de Arquivos (CONARQ) e, 19 anos depois, a Câmara Técnica de Documentos Audiovisuais, Iconográficos, Sonoros e Musicais (CTDAISM), que surgiu "a partir da carência de uma terminologia arquivística própria e normalizada referente à documentação audiovisual, [...], de que o tratamento técnico destes documentos demanda de metodologia específica".

Os participantes das CineOP foram testemunhas de uma separação inicial entre os arquivistas e os profissionais de preservação audiovisual das demais áreas de formação, assim como também presenciaram sua aproximação, ao longo das edições. Do total de 17 cursos de Arquivologia em universidades 
estaduais e federais, três possuem uma disciplina obrigatória e específica para o audiovisual, quatro oferecem disciplinas que mencionam o audiovisual e duas oferecem disciplinas optativas ${ }^{8}$. Como resultado, o audiovisual foi tema de poucos trabalhos acadêmicos da Arquivologia9 .

Enquanto a Arquivologia aborda o audiovisual de forma periférica, na prática os profissionais com outras formações que atuam na contemporaneidade no campo da preservação audiovisual contaram com restrito contato com a teoria da Arquivologia tradicional. Tal condição torna inadequado o uso do termo 'arquivista audiovisual' para uma significativa parcela de profissionais brasileiros.

Não há unicidade na autodenominação dos profissionais, o que constitui indicativo da fragilidade da profissão. Em currículos, páginas no Linkedln, sites pessoais e na plataforma Lattes há registros como "especialista em" (preservação/restauração), "técnica/o em”,"“conservador/a audiovisual”,"preservador/a audiovisual" e "preservacionista audiovisual". Neste artigo desconsidero os termos "especialista" e "técnico/a", por considerá-los genéricos. Acrescente-se o termo "conservador/a", pelo fato de seu vínculo ser apenas a uma parcela - ainda que muito importante - da preservação audiovisual, a da conservação, mas sobretudo por seu segundo significado, de "indivíduo afeito a ideias e costumes antiquados, já ultrapassados, manifestando-se contrário a quaisquer mudanças da ordem estabelecida" (Michaelis, 2018). Já "preservador/a audiovisual” impõe a (pouca) prática flexão de gênero, enquanto a supressão de gênero, "preservadorx", seria controversa. O termo "preservacionista" foi observado pela primeira vez na Dissertação no Programa de Pós-Graduação em Imagem e Som da Universidade Federal de São Carlos (UFSCar) de Lila Foster (20 10: 3), dedicada "à nova geração de preservacionistas audiovisuais" , em provável tradução do termo em inglês "preservationist", habitual nos EUA e Inglaterra. O termo em português, com utilização frequente e corriqueira no campo da ecologia, é usado neste artigo.

À exceção da França e destes países de língua inglesa, o Brasil segue a tendência mundial de falta de denominação própria para este ofício. Na Áustria não há formação acadêmica em preservação audiovisual, mas em "Archivwissenschaft und Medienarchive" (Arquivologia e Arquivos de Mídia) - formando profissionais atuantes em museus, com foco em arquivo, conservação, restauração e estratégias expositivas - e em "Digitales Sammlungsmanagement” (Gestão de Coleções Digitais), compreendendo também o audiovisual. Usualmente os profissionais atuantes na preservação audiovisual se autodenominam "filmarchivist" e "filmrestaurator", mas não se trata de uma nomenclatura oficial. No Japão, Eslovênia e México também não há uma definição e regulamentação da profissão, sendo utilizados, respectivamente, os termos "audiovisual archivist" (arquivista audiovisual), "konservator-restavrator avdiovizualne dediščine" (conservador-restaurador do patrimônio audiovisual) e "conservador audiovisual”, informalmente ${ }^{10}$.

A atuação de um preservacionista audiovisual possui vinculação à dos demais "profissionais da memória", arquivistas e museólogos, no que tange às estratégias, atuações - de conservação, catalogação e administração - e pre-

8 Pesquisa feita em outubro de 2018 por e-mails às universidades UEL, UEPB, UFAM, UFBA, UFES, UFF, UFMG, UFPA, UFPB, UFRG, UFRGS, UFRJ, UFSC, UFSM, UnB, UNESP e UNIRIO. Sete não responderam, mas informações foram obtidas pelos sites da instituição.

9 Como Costa (2007), Silva (20|3) e Vieira (20/4), informado pelo arquivista audiovisual Antonio Laurindo. Não foi encontrada referência anterior para a designação dos profissionais em publicações, e-mails e sites.

10 Quatro países selecionados a título de ilustração. Informações fornecidas por Anna Dobringer, Nadja Šičarov, Hitomi Matsuyama e Alfredo Rodriguez, a quem agradeço. 
ocupações - especialmente em relação à preservação digital. No entanto, ao contrário dos preservacionistas audiovisuais, o ofício de arquivista e museólogo é reconhecido pela Classificação Brasileira de Ocupações (CBO) do Ministério do Trabalho, e foi regulamentado por leis em 1978 e 1984, respectivamente, com fiscalização por conselhos próprios.

Conforme o Artigo $5^{\circ}$ da Constituição da República Federativa do Brasil, a regulação de profissões é prevista, sendo "livre o exercício de qualquer trabalho, ofício ou profissão, atendidas as qualificações profissionais que a lei estabelecer" (Brasil, 1988). Para a inclusão de uma nova ocupação na Classificação Brasileira de Ocupações (CBO) do Ministério do Trabalho é necessário indicar a "quantidade de profissionais atuando na área; atividades exercidas pelo ocupante; entidades formadoras; e escolaridade requerida". A dificuldade de endereçar cada um destes quatro requisitos para inclusão na CBO denota a incipiência da profissão e a crise de identidade dos profissionais.

Os preservacionistas têm debatido e publicizado algumas das questões cruciais para o reconhecimento da profissão. $O$ estatuto da ABPA datado de $20 \mathrm{II}$ indica, como uma de suas finalidades, "contribuir para o desenvolvimento e aperfeiçoamento técnico, científico e cultural dos profissionais, entidades e instituições que atuam no campo da Preservação Audiovisual". A cada edição da CineOP é redigida uma carta, reafirmando o evento como fórum de discussão para questões atinentes à preservação e valorização do patrimônio audiovisual brasileiro, com propostas de ações para sua salvaguarda. A temática da profissionalização está presente em alguns destes documentos, com destaque para, dentre as medidas mais urgentes elencadas na Carta de Ouro Preto de 2012 e dentre as proposições e demandas da Carta de 2013:

\footnotetext{
A formalização do campo da preservação audiovisual como um saber específico, uma profissão particular - iniciando a luta pelo reconhecimento da categoria junto às instâncias reguladoras do trabalho no País - e uma ação necessária à constituição do patrimônio cultural brasileiro (Carta 20I2).

Incluir na legislação o reconhecimento de profissionais de preservação audiovisual, considerando sua multidisciplinaridade e formações diferenciadas, sem excluir ou restringir o exercício profissional a uma determinada categoria (Carta 2013).
}

O Plano Nacional de Preservação Audiovisual (PNPA) é um documento de diagnóstico e proposições de ações e políticas para o campo da preservação audiovisual. Sua redação final foi aprovada em assembleia da ABPA em 2016. Contudo, devido ao contexto político do então recente golpe presidencial com o impeachment da Presidente Dilma Rousseff, não percorreu os gabinetes do MinC e Ministério da Educação (MEC). Portanto, não ganhou alcance, tornando-se somente uma referência, uma carta de intenções. Entre os objetivos do PNPA, destaca-se aquele articulado à profissionalização:

7. Incentivar o reconhecimento, a valorização e a regulamentação profissional. [por meio de ações:]

7.I Buscar recursos para manutenção e ampliação do quadro funcional das instituições, incluindo a promoção de concursos públicos. 7.2. Revisar as regras de formulação dos concursos públicos, tendo em vista a adequação da formação técnica dos futuros funcionários 
às necessidades e especificidades do setor.

7.3. Criar estratégias que garantam a estabilidade de profissionais para que se cumpram determinados projetos em curso nas instituições.

7.4. Propor e defender junto ao Congresso Nacional e ao Governo Federal a aprovação de legislação visando o reconhecimento e regulamentação profissional de pesquisadores que atuam na área de preservação audiovisual (2016:6).

Em 2010 foi constituído um Grupo de Trabalho de Preservação Fluminense, pela Secretaria de Estado de Cultura do Rio de Janeiro (SEC-RJ), com representantes do Arquivo Geral da Cidade, Arquivo Nacional, Cinemateca do MAM-RJ, CTAv, Labocine, MIS e UFF. Os estudos do Grupo de Trabalho foram absorvidos no Plano Setorial do Audiovisual do Plano Estadual de Cultura do Rio de Janeiro, publicizado em 20I5, com a identificação de "deficiência de mão-de-obra técnica e especializada para tratar da atividade de preservação dos conteúdos audiovisuais em seus mais diversos formatos" (SEC, 20I5: 23).

Em diversos seminários e debates, a questão da profissionalização é comentada. Destaca-se o "Seminário Internacional de Preservação Audiovisual no Mercosul”, realizado em Salvador em 2016. No evento, foi produzida uma declaração de compromisso, para o desenvolvimento da preservação do patrimônio audiovisual dos países integrantes do Mercosul, com ênfase para as recomendações:

Melhorar a formação e a capacitação na área da preservação audiovisual:promover a inclusão de disciplinas de preservação audiovisual nos currículos dos cursos universitários de cinema e audiovisual; arquivologia; biblioteconomia; museologia etc.; buscar a transmissão dos saberes e ofícios associados à preservação, alguns deles em risco de desaparição; incorporar novos enfoques disciplinares e interdisciplinares no marco da preservação digital (ciências da informação, engenharia, etc.) [...] (Salvador, 20l6).

A classe de preservacionistas vem buscando chamar a atenção para questões concernentes à formação e profissionalização, em meio a outros assuntos da área, com uso destes documentos, e em outros eventos.

A identificação e quantificação de profissionais atuantes na área é uma difícil tarefa. Na ABPA, cuja missão contempla "contribuir para o desenvolvimento e aperfeiçoamento técnico, científico e cultural dos profissionais que atuam no campo da preservação audiovisual” (ABPA, 20I8), não há indicação de requisito para sua afiliação e dentre os associados estão pesquisadores, realizadores, gestores culturais, fotógrafos, herdeiros de acervos audiovisuais, e preservacionistas audiovisuais. A lista de discussão é uma plataforma de comunicação de caráter informativo, que eventualmente propicia debates aprofundados e está aberta "ao público geral interessado em preservação audiovisual" I .

A instabilidade profissional resultante da falta de políticas e a oscilação da saúde das instituições tem acarretado, além da alarmante evasão profissional, a

II A falta de requisito (como currículo ou comprovação de experiência) e a filiação de profissionais com interesse na área da preservação audiovisual é uma situação análoga à de associações estrangeiras, como a Association of Moving Image Archivists (AMIA) e International Association of Sound and Audiovisual Archives (IASA). 
atuação em outras áreas, que pode denotar personalidades profissionais múltiplas. A atuação em variados campos do audiovisual, para além da preservação, e o consequente acúmulo de credenciais remonta à atuação dos pioneiros do campo da preservação audiovisual. Em 1956 Paulo Emílio Sales Gomes tornou-se o Conservador-Chefe da Cinemateca Brasileira, mas frequentemente é mais conhecido por sua atuação como pesquisador, professor, ensaísta e crítico. $\bigcirc$ mesmo ocorre com Rudá de Andrade, Caio Scheiby, Maria Rita Galvão, Ruy Pereira da Silva e Cosme Alves Netto, figuras cruciais para a preservação audiovisual, e a criação e fortalecimento das cinematecas.

Por décadas a formação dos técnicos ocorreu em instituições, de uma geração a outra, do aprendizado na prática. Essa dinâmica é viável na medida em que as instituições mantenham uma constância de recursos para a manutenção de suas equipes. As instituições passaram por formas de contratação temporárias ou por terceirização, inviabilizando a continuidade dos trabalhos, desperdiçando recursos humanos e financeiros investidos na formação e, eventualmente, acarretando evasão profissional. Neste cenário, profissionais abnegados tornam-se voluntários, prática comum e pouco saudável.

$\mathrm{Na}$ ausência ou precariedade da manutenção de um corpo técnico de funcionários, projetos de longa duração são importante fonte de iniciativas de formação nas instituições. Das últimas décadas, destacam-se os projetos de "Censo Cinematográfico”, na Cinemateca Brasileira e na Cinemateca do MAM-RJ, a partir de 200I, no qual um grupo de estagiários foi formado e, no momento presente, uma parcela deste grupo integra o corpo de preservacionistas audiovisuais atuantes em instituições, ou de forma independente.

A partir do segundo semestre de 2003 foram oferecidos estágios de formação, com duração de duas semanas, pela Cinemateca Brasileira, para representantes de arquivos de todos os estados brasileiros. Em outros anos, técnicos da instituição da Cinemateca Brasileira e Cinemateca do MAM-RJ fizeram consultoria e formação em outros arquivos.

No campo da formação no âmbito acadêmico, destaca-se a disciplina optativa sobre preservação audiovisual oferecida na UFF a partir de 2000, elaborada por João Luiz Vieira e Hernani Heffner, ministrada por este último durante quatro anos. Em 2005 a disciplina "Memória e Políticas de acervos audiovisuais" torna-se obrigatória, a partir de reivindicação do corpo discente do curso de Cinema e Audiovisual. Os documentos finais dos Congressos de 2003 e 2011 do Fórum Brasileiro de Ensino de Cinema e Audiovisual (Forcine) enfatizaram a importância de elaboração de um diagnóstico dos acervos da produção universitária dos cursos de Cinema e Audiovisual, a inclusão de disciplina e o fomento à pesquisa sobre preservação (Rodrigues, 20I5: 180). A Resolução $n^{\circ} 10$ do Conselho Nacional de Educação de 2006 institui as Diretrizes Curriculares Nacionais do Curso de Graduação de Cinema e Audiovisual e determina que a preservação audiovisual seja um dos eixos para atividades acadêmicas:

Art. $3^{\circ} \mathrm{O}$ egresso do curso de Cinema e Audiovisual deve estar capacitado nas seguintes áreas:

c) Teoria, análise e crítica do cinema e do audiovisual - voltada para a pesquisa acadêmica nos campos da história, da estética, da crítica e da preservação.

Art. $6^{\circ} \mathrm{O}$ currículo do curso de Cinema e Audiovisual de cada IES deve conter atividades acadêmicas que contemplem os seguintes eixos:

4. Economia e Política - eixo pautado pelas questões ligadas à ges- 
tão e à produção, à distribuição e à exibição, levando-se em conta o potencial de inovação tecnológica da área. Contemplam ainda as questões referentes à ética e à legislação, como também as políticas públicas para o setor, incluindo as de preservação e de restauração dos acervos (BRASIL, 2006).

Em pesquisa coordenada por Rodrigues (20I5: I8I), com professores de 20 universidades, alguns docentes demonstraram interesse na inclusão de disciplina sobre preservação audiovisual, mas alegaram dificuldades na própria estrutura acadêmica, falta de recursos e escassez de profissionais com formação. Este último dado pode ser associado ao secular dilema: ovo ou galinha.

Apesar da Diretriz de 2006, a preservação está contemplada em poucos programas de bacharelado em cinema e audiovisual. Dentre os 42 programas pesquisados $^{12}$, dos quais 19 são públicos, além da UFF, sete oferecem disciplinas obrigatórias sobre o assunto - o Instituto Federal de Goiás (IFG), a Universidade Federal da Integração Latino-Americana (UNILA), a Universidade Federal do Pará (UFPA), a Universidade Estadual do Sudoeste da Bahia (UESB), a Faculdade Estácio de Sá, a Faculdades Integradas Hélio Alonso (FACHA) e o Centro Universitário UNA (Una). A Universidade Federal de Pelotas (UFPel) e a Universidade Federal de Pernambuco (UFPE) oferecem disciplinas optativas, sem informação sobre sua periodicidade.

A preservação audiovisual é crucial também na construção de acervos das universidades, sobretudo da produção discente. Rodrigues (2005: 182) destaca acervos da Pontifícia Universidade Católica do Rio Grande do Sul (PUCRS), Fundação Armando Alvares Penteado (FAAP) e a UFF, que recentemente lançou - Laboratório Universitário de Preservação Audiovisual (LUPA) - inicialmente pensado como Cinemateca Universitária Fluminense, e hoje abarcando a produção órfã fluminense, além da produção universitária (Freire, 2018).

A Escola de Comunicações e Artes da Universidade de São Paulo (ECA-USP), apesar de seu programa de Curso Superior do Audiovisual não abranger a preservação, foi de suma importância para o desenvolvimento da área, sobretudo pela atuação de Paulo Emílio Salles Gomes como professor, engajando muitos alunos que se envolveram com a preservação e posteriormente atuaram na Cinemateca Brasileira, como Carlos Augusto Calil, Carlos Roberto de Souza, Maria Rita Galvão, José Carvalho Motta e Sylvia Bahiense Naves (Coelho, 2009: II).Ainda, na organização de seminários em seu Programa de Pós-graduação, e com publicação de dissertações e teses, com destaque para quatro preservacionistas da Cinemateca Brasileira: Francisco Mattos (2002), Olga Futemma (2006), Fernanda Coelho (2009), e a tese de Carlos Roberto de Souza (2009). Em 2018 é ministrada a disciplina "Preservação Audiovisual na América Latina: Questões Conceituais e Historiográficas”, por Fabián Núñez e Eduardo Morettin.

O Programa de Pós-Graduação em Memória Social da Universidade Federal do Estado do Rio de Janeiro (UNIRIO) não possui disciplinas acerca do assunto, mas são muitas as dissertações e teses em torno da preservação audiovisual. A tese de Silvia Ramos Gomes da Costa em torno das ondas de destruição do audiovisual apresenta uma pesquisa sobre as publicações de mestrado e doutorado em outras áreas, como Direito, História, Ciência da Informação,

12 Pesquisa efetuada em outubro de 2018 , nos sites dos programas de cinema e audiovisual das universidades AESO, Senac, CEUNSP, ESPM, FAAP, FTC-BA, IESB, Infnet, PUCMinas, PUCRio, PUCRS, UEG, UFC, Ufes, UFPE, UFRB, UFS, UFSC, UFSCar, UnB, Unespar, Unicamp, Unifor, Unijorge, UNIMEP, UNIMONTE, UNISC, Unisinos, UniSociesc, Unisul, AnhembiMorumbi, USP, além das citadas no texto. 
Antropologia Social e Artes Visuais (2012: 16).

No âmbito acadêmico, não há curso de formação específica na área no Brasil.A disciplina sobre preservação audiovisual ministrada na UFF desde 2000, pioneira no ensino de cinema e audiovisual, consistiu em um pontapé inicial para muitos preservacionistas, ainda se tratando de uma disciplina dentre várias. Acrescente-se o dado acerca do estímulo à criação de uma consciência sobre a importância da preservação, para alguns alunos que atuam em outras áreas do audiovisual. $O$ mesmo não pode ser afirmado em relação a profissionais formados em programas acadêmicos sem disciplina sobre a preservação audiovisual. Ressalta-se que, ao contrário da tendência de "cineastas" e técnicos autodidatas de períodos passados, majoritariamente, os jovens profissionais que atuam hoje no mercado de trabalho possuem bacharelado em cinema e audiovisual (ou similares). De acordo com Rodrigues (2015: 180), "se não forem nas escolas, quem mais poderá ser responsabilizar pela formação sistemática de especialistas em criação e preservação de acervos?".

Programas de formação, de curta e média duração, têm sido realizados, em complemento à academia. Destacam-se as oficinas de catalogação e documentação, preservação e restauração audiovisual na Cinemateca Brasileira, em 2014, e no Arquivo Nacional no âmbito do Festival de Cinema Arquivo em Cartaz, cursos no Centro de Pesquisa e Formação do Sesc, como A Restauração Audiovisual e o Patrimônio Fílmico Latinoamericano e Preservação audiovisual: história, conceitos, práticas - organizado em 2016 como parte do evento "I00 Paulo Emílio”, em comemoração ao centenário de nascimento de Paulo Emílio Salles Gomes, no qual foram organizados outros cursos, em especial um sobre a preservação audiovisual, na Cinemateca Brasileira.

No Brasil foram algumas as iniciativas de formação que não saíram do papel. A Embrafilme e o CTAv, com apoio técnico da Cinemateca Brasileira, planejaram o curso Formação de operadores de preservação / áreas de filme e vídeo" (Embrafilme, 198-), previsto com carga horária de 48 horas para instituições convidadas, com cotas regionais. Não foi possível comprovar a execução deste curso, sendo a minuta do programa o único documento encontrado. Outra iniciativa não efetivada foi o curso de capacitação organizado pela ABPA, CTAv e SAv - de Preservação de Materiais Audiovisuais Digitais, Workflow de Cinema,Televisão e Vídeo Digital para Preservadores Audiovisuais, Restauração Fotoquímica e Digital de Filmes e Projeção Cinematográfica em Película. Anunciados pela então Secretária do Audiovisual na CineOP em 2012 e por convite eletrônico pelo então Secretário do Audiovisual para realização em outubro de 2013, o que nunca ocorreu ${ }^{13}$. Em 2018 foi lançado o Edital CTAv/SAv/MinC de Formação Audiovisual com previsão de até $\mathrm{R} \$$ 16, I milhões do FSA para formação e capacitação de profissionais, inclusive os de preservação ${ }^{14}$.

Além da citada CineOP, seminários e simpósios foram eventos importantes para a projeção de visibilidade à área, como o "Simpósio sobre o Cinema e a Memória do Brasil" em 1979, organizado pela Embrafilme (Souza, 2009: 126); o "Fórum sobre Preservação e Restauração de filmes no Brasil e na América Latina” em 2005 (em decorrência do I Estágio Ibermedia de Restauração Digital); inúmeros debates realizados no Instituto Moreira Salles (IMS); seminários recentes, organizados pela Fundação Joaquim Nabuco (Fundaj) e Universidade Federal do Recôncavo da Bahia (UFRB). O congresso da FIAF em 2006, organizado

I3 Na CineOP de 2018, a representante da Ancine publicizou esta iniciativa como se tivesse sido realizada. 14 Considerando que só produtoras cadastradas na Ancine poderão se inscrever, provavelmente a chance de realização de curso para preservação será restrita. 
e abrigado pela Cinemateca Brasileira, para além da projeção do Brasil na área da preservação mundo afora, foi uma oportunidade de formação técnica para a equipe que montou o congresso, bem como para o público brasileiro presente.

Cursos de formação em instituições fora do Brasil foram relevantes para os preservacionistas brasileiros, notadamente os cursos de verão da FIAF; a escola The L. Jeffrey Selznick School of Film Preservation, em Rochester, principal programa de formação com viés técnico; estágios na Filmoteca Española; o mestrado "Heritage Studies: Preservation and Presentation of the Moving Image", da Universiteit van Amsterdam em parceria com o EYE Filmmuseum; e o programa de "Valorisation des patrimoines", da Université Paris 8, dentre outros. Alguns relatos foram compartilhados no "I Painel de Preservação Audiovisual: Formação e Experiências Internacionais" na Cinemateca do MAM-RJ em 2010 e em "Reflexões sobre a preservação audiovisual 2016-2015: 10 anos da CineOP" (Universo, 20I5).

As iniciativas pessoais de formação fora do Brasil reforçam a importância de uma formação própria ou especialização no Brasil. Para tanto, João Luiz Vieira (2015: 190) propõe dois eixos de formação. O primeiro, de capacitação e atualização dos profissionais atuantes em instituições, considerando a regionalização e as especificidades de cada instituição. $O$ outro, orientado pela articulação entre universidades e arquivos, dirigida para uma formação teórica e prática. A proposição vai ao encontro do caminho indicado por Edmondson (2002: 7I), de treinamento em instituições mais estruturadas, para uma formação como obrigação profissional de seu corpo técnico, e incorporação desta função em seus orçamentos. Nos moldes da escola na George Eastman Museum, na qual a formação está adaptada ao fluxo de trabalho - em correspondência com a formação na medicina com seus hospitais-escolas $\neg-$ ou no mestrado em Amsterdam, onde alguns dos recém-formados passam a trabalhar no EYE Filmuseum.

Para registrar a profissão de preservacionista audiovisual na $C B O$ é requisitada uma definição de atividades exercidas pelo profissional. Como modo de detalhar tais atividades, segue outra definição do campo da preservação audiovisual:

A totalidade de operações necessárias para assegurar o acesso permanente a documentos audiovisuais no maior grau de sua integridade. Ela pode englobar um grande número de procedimentos, princípios, atitudes, equipamentos e atividades. A preservação engloba a conservação e a restauração de suportes; a reconstituição de versões originais; a copiagem e o processamento do conteúdo visual e/ou sonoro; a digitalização para criação de cópias com finalidade de acesso ou preservação; a manutenção dos suportes em condições adequadas de armazenamento; a recriação ou emulação de procedimentos técnicos obsoletos, de equipamentos e de condições de apresentação; a pesquisa e a coleta de informações para levar a bom termo essas atividades (Edmondson, 2017: 23).

Cada ação identificada envolve múltiplos e variados conhecimentos técnicos vinculados, oriundos de diversos campos das ciências humanas, exatas e sociais aplicadas, desde administração, até meteorologia. Ainda que exista a especialização em certa área específica, para a atuação de preservacionistas é desejável um conhecimento mais amplo da área, seja para garantir profissionais mais completos ou para promover a capacidade de resiliência em momentos de 
adversidade.

Considerando as produções contemporâneas, a digitalização, as formas de acesso e a gestão de dados em geral, a preservação digital impõe um conhecimento específico, imprescindível ao preservacionista audiovisual hoje. Saberes aprofundados em preservação digital - em eletrônica, softwares, hardwares, servidores, base de dados, estratégias e migração de suportes, repositórios, entre outros - não têm sido contemplados em cursos e nas demais formações. Ressalta-se que, diante da incessante mudança da tecnologia e de práticas de mercado, é vital a constante atualização dos saberes. Diante da escassez de investimentos na atividade de preservação digital, são poucos os profissionais que alcançam o montante de conhecimentos de forma ampla, seja de forma prática ou por meio de pesquisas ${ }^{15}$, tornando crítica a atualização dos preservacionistas atuantes. A terceirização de serviços e a atuação de profissionais de $\mathrm{TI}$ na gestão de um acervo audiovisual digital potencialmente não abrangem as especificidades de um arquivo de filmes, de utilização de soluções não proprietárias (mandatório na ótica da preservação), na documentação e de construção de estratégias resilientes e integradas. Esta é uma tendência notada no Brasil, além de relatos de preservacionistas de outros países com problemas com empresas terceirizadas como a falta de acesso à estrutura de banco de dados ou critérios insuficientes para gerar materiais de preservação em projetos de digitalização.

Um tema vinculado à atuação do preservacionista é a fratura entre os preservacionistas e os profissionais do audiovisual das demais áreas. Em muitos países, o acervo audiovisual foi reconhecido como um ativo a ser explorado comercialmente.Tal condição impulsionou a consciência em torno da preservação. O mesmo não ocorreu no Brasil em larga escala, pois muitos materiais chegam aos arquivos de filmes com marcas de negligência, evidenciando a importância de convencimento de muitos produtores acerca da relevância da preservação de seu acervo ${ }^{16}$.

O teórico da cultura digital Peter Kaufman (20I8: I2) identifica a aproximação com realizadores e produtores como uma, dentre dez recomendações, para engajamento na construção de uma nova perspectiva para profissionais de preservação audiovisual para a próxima década, citando que a aplicação de princípios de arquivamento à produção é tão importante quanto aplicar princípios de produção ao arquivamento. A título de exemplo, as teorias e práticas de arquivamento e preservação audiovisual contam com restrita aplicabilidade atualmente em produtoras, se limitando ao Sistemas de Gerenciamento de Conteúdo - MAM e à parâmetros para a pós-produção de obras.Após o fim de seu principal percurso comercial, usualmente as obras são negligenciadas.

Outros indícios desta desconexão entre a produção e a preservação são as baixas taxas de aprovação técnica de materiais em caráter de Depósito Legal, conforme reportado nos relatórios anuais da Cinemateca Brasileira de 2016 e 2017. Produtores audiovisuais são frequentemente imbuídos de imediatismo na produção dos materiais para finalizar a prestação de contas do projeto junto à Ancine, o que não condiz com práticas da preservação.

Figura I: Comparativo dos investimentos do FSA (em desenvolvimento de projeto, produção, coprodução e comercialização de obras de longa-metragem,

I5 A título de ilustração, cito lgor Calado, responsável por uma extensa pesquisa sobre preservação digital na UFPE; Marco Dreer, preservacionista especializado em documentos sonoros e Rodrigo Mercês, coordenador do setor de Preservação de Filmes da Cinemateca Brasileira.

16 Meu testemunho a partir de experiência em arquivos de filmes. Alguns produtores, realizadores e técnicos são celebradas exceções no Brasil. 
televisão e jogos eletrônicos) e do orçamento da Cinemateca Brasileira, no período de 2009 a 2017.

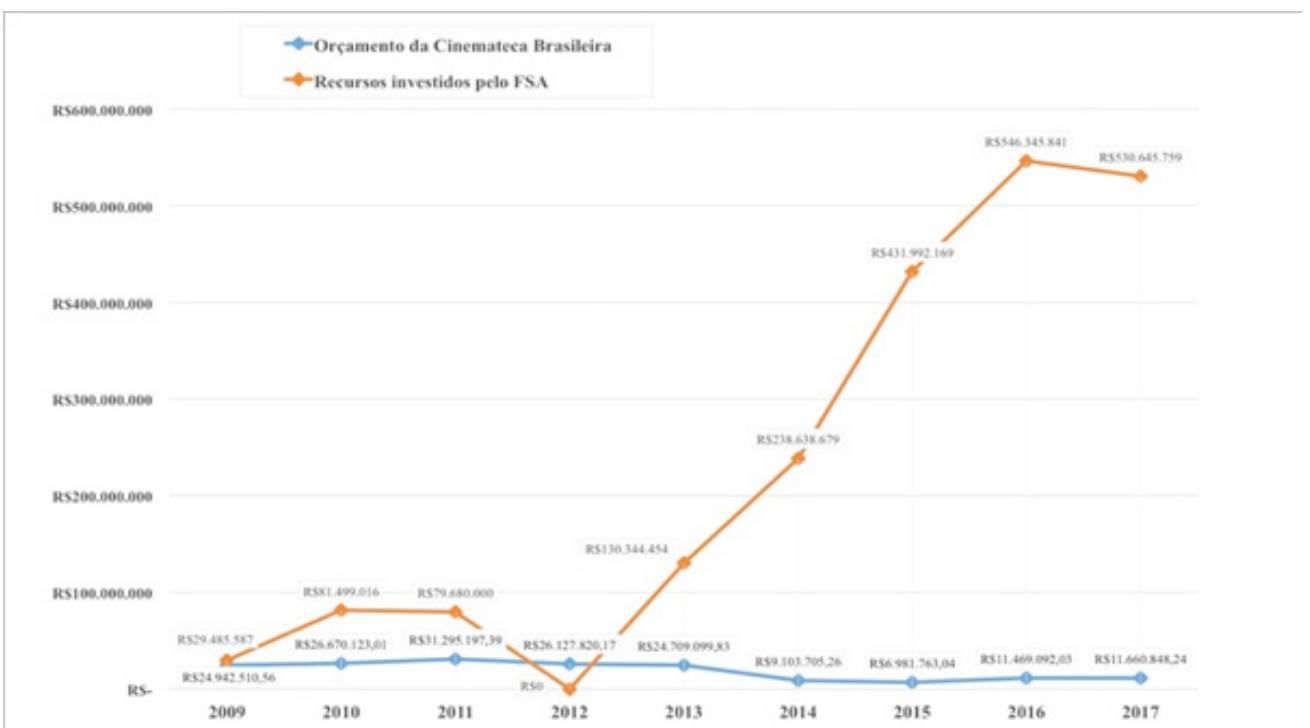

Figura I: Comparativo dos investimentos do FSA (em desenvolvimento de projeto, produção, coprodução e comercialização de obras de longa-metragem, televisão e jogos eletrônicos) e do orçamento da Cinemateca Brasileira, no período de 2009 a 2017. ${ }^{17}$

O número de obras a serem incorporadas como Depósito Legal aumentou ao longo da década, como resultado de uma sólida política de investimentos, sobretudo do Fundo Setorial do Audiovisual (FSA). O audiovisual é notoriamente uma indústria cara, que emprega um número expressivo de profissionais e que eventualmente possibilita um retorno financeiro ou cultural ${ }^{18}$. Na edição de 2018 da CineOP ocorreu o debate intitulado 'Fronteiras entre a indústria, mercado e arquivos - conteúdo, fomento e regulação', com convidados da Ancine, MinC, mercado exibidor e um representante da indústria cinematográfica e audiovisual no Comitê Gestor do FSA, que identificou uma aproximação necessária entre os preservacionistas e o setor produtivo. Contudo, sugeriu a busca de outro caminho de financiamento, distinto do FSA, uma vez que este se tornou a única fonte para investimentos em todas as áreas do audiovisual e que seria mais adequado criar caminhos de forma independente, para soluções mais duradouras e efetivas. Cabe aqui ressaltar que a preservação está contemplada no Plano de Diretrizes e Metas para o Audiovisual 20 I I-2020 publicizado pela Ancine, na Diretriz 9, Promover a Preservação, Difusão, Reconhecimento e Cultura Crítica do Audiovisual Brasileiro:

\footnotetext{
A atenção aos acervos e a guarda adequada dos conteúdos produzidos dizem muito da maturidade de uma indústria audiovisual. Mas o tratamento da memória audiovisual perde muito do seu sentido
}

17 Fontes: sites do FSA e Cinemateca Brasileira. A Cinemateca Brasileira é a única instituição que recebe materiais em Depósito Legal e, conforme a citação de Bezerra (20I5: 2) na introdução deste artigo, seu orçamento representa quase que a totalidade de investimentos em produção audiovisual, no período, no país. Desta forma, considero o gráfico uma ilustração direta do desnível de investimentos em produção e preservação audiovisual.

180 índice de market share de ingressos de filmes brasileiros teve média 13,6\% em dez anos, até 2017 Tal índice parece-me tímido diante de tamanho investimento em produção. Por outro lado, a produção de cinema não comercial tem tido notável repercussão no circuito de festivais nacionais e internacionais. 
se reduzido às ações de guarda e acervamento. [...] Assim, a guarda e acervamento se fortalecem e completam na medida em que as obras são devolvidas ou mantidas em circulação, resignificando-se e influenciando as novas produções (Ancine, 2013: 95).

A Diretriz reforça a importância da preservação segundo a perspectiva do acesso. $O$ acesso é um elemento fundamental no conceito da preservação audiovisual, que só pode ser viabilizado mediante as demais ações de preservação, para garantir a integridade do documento audiovisual. A demanda por acesso ao acervo audiovisual tem aumentado, em decorrência dos investimentos do FSA - principalmente para inclusão das novas obras. Para atender as demandas de acesso geradas pelo crescimento da indústria, é necessário proporcionalizar o investimento em preservação, para gerar as condições necessárias para a salvaguarda das obras e a criação de materiais de acesso.

Nós, preservacionistas, entendemos a importância do acesso, queremos promover e fomentar formas criativas de difusão de acervos; seu uso por pesquisadores de imagem para novas obras, historiadores e sociólogos; a criação de ferramentas para sua contextualização; o acesso para fomentar a educação e o exercício da cidadania.

A regulamentação da profissão poderia ser uma medida para a consolidação da identidade profissional e de seu exercício, um impulso para o reconhecimento da relevância da preservação, e uma credencial para o diálogo com os colegas do audiovisual. No conturbado momento político do final do ano 2018, há um prenúncio de mudanças no Ministério do Trabalho e da Cultura, com a possibilidade de resultar na perda do status de ministério, para incorporação em outras instâncias. Neste cenário, os profissionais potencialmente terão outras preocupações e frentes de oposição, em lugar de advogar pelo reconhecimento da profissão. $O$ processo eleitoral no Brasil em 2018, em parte baseado na desinformação e disseminação de notícias falsas, é um alerta para a importância dos profissionais de memória. A aproximação crucial de arquivos audiovisuais com agentes da mídia que, nestes novos tempos, atuam na conferência e correção de falsas informações distribuídas online (Kaufman, 20 I8: I3).

O incêndio em 2016 em parte do depósito de película de nitrato de celulose na Cinemateca Brasileira, o quarto da instituição, e a reação pífia do poder público apontam forte negligência, e a necessidade de fortalecimento de políticas de patrimônio. Um indício do "empreendimento" identificado pelo jornalista Leonardo Sakamoto à época do incêndio que destruiu o acervo de 200 anos do Museu Nacional em 2018, de "um projeto coletivo, pacientemente implementado ao longo do tempo por um Estado e uma sociedade que condenaram seu patrimônio histórico, natural, científico e cultural à inanição" (20l8). No caso da preservação audiovisual, cabe incluir a letárgica conivência da cadeia do audiovisual com o descaso com seu patrimônio, o que propicia mais revezes para a sua preservação.

Nos últimos anos, a profissão do preservacionista foi caracterizada pela instabilidade; paralisação de trabalhos; precariedade dos vínculos empregatícios, contratação por meio de projetos de tempo determinado; salários estipulados aquém das responsabilidades; variação em torno dos investimentos na área, segundo os ventos políticos. Tal panorama se opõe aos pilares do funcionamento de instituições, da necessidade de recursos financeiros constantes, atuação de técnicos especialistas e estabilidade de fluxos de trabalho, "a preservação não é uma operação pontual, mas uma tarefa de gestão que não acaba nunca” (Edmon- 
dson, 2017: 24).As práticas de mercado em constante transformação, a inovação na criação e outras formas de produção audiovisual (como jogos eletrônicos, realidade virtual, multiplataforma), a descontinuidade de laboratórios comerciais e a obsolescência e o desenvolvimento tecnológico impõem expressivos e custosos desafios às práticas de preservação.

Preservacionistas desejam remover a noção de utopia e de vocação quixotesca pelo patrimônio audiovisual, que permeia seu trabalho. Não queremos passar pelo desterro pessoal e profissional detectado por Paulo Emílio Sales Gomes em 1960 (2016: 5I) de "a longo prazo [...] a ação sem consequências ponderáveis provoca certa secura capaz de alterar profundamente uma personalidade". Queremos parar de testemunhar ondas de destruição do patrimônio audiovisual, e que este passe a ser integrado às instituições de patrimônio e museológicas. A precariedade da formação, a inconstância dos trabalhos e a evasão de preservadores audiovisuais acarretam prejuízos expressivos ao patrimônio audiovisual. Os preservacionistas anseiam por atuar na consolidação da área, por meio de políticas públicas, de formação específica, para atingir a estabilidade das instituições e o reconhecimento do patrimônio audiovisual como parcela integrante da identidade nacional.

\section{Referências}

BEZERRA, Laura.A Unesco e a Preservação do Patrimônio Audiovisual. In: Anais V ENECULT. Universidade Federal da Bahia, Salvador, 2009.

. Políticas para a preservação audiovisual no Brasil (I995-2010) ou: "Para que eles continuem vivos através de modos de vê-los”. 20I4. Tese (Doutorado). Universidade Federal da Bahia, Salvador, 2014.

. A preservação audiovisual no Brasil contemporâneo. HEFFNER, H; D'ANGELO, Raquel H; D'ANGELO, Fernanda H. (orgs.). Reflexões sobre a preservação audiovisual 20 I6-20 I5: I0 anos da CineOP. Ouro Preto: Universo, 2015. p.28-30.

COELHO, Fernanda. A Experiência Brasileira na Conservação de Acervos Audiovisuais. Dissertação (Mestrado). Universidade de São Paulo, São Paulo, 2009.

. A conservação audiovisual no Brasil: apontamentos, conquistas e desafios. HEFFNER, H; D’ANGELO, Raquel H; D’ANGELO, Fernanda H. (orgs.). Reflexões sobre a preservação audiovisual 2016-2015: 10 anos da CineOP. Ouro Preto: Universo, 2015. p. II6-II9.

CINEARTE, Editorial. Rio de Janeiro, ano IV, n. I54, I929, p.7.

COSTA, Alessandro. Gestão arquivística na era do cinema digital: formação de acervos de documentos digitais provindos da prática cinematográfica. 2007. Tese (Doutorado), Universidade Federal de Minas Gerais, Belo Horizonte, 2007.

COSTA, Silvia. As ondas de destruição: a efemeridade do artefato tecnológico e o desafio da preservação audiovisual. 2013. Dissertação (Mestrado). Universidade Federal do Estado do Rio de Janeiro, Rio de Janeiro, 2013.

EDMONDSON, Ray. Arquivística audiovisual: filosofia e princípios. Tradução de Carlos Roberto Rodrigues de Souza. 3.ed. Brasília: Unesco, 2017.

. Rochester Reflections - The I0th FIAF Summer School, and Beyond. Journal of Film Preservation. 2002, n.65.

EMBRAFILME. Formação de operadores de preservação: áreas de filme e vídeo: minuta de curso. Rio de Janeiro, 198-.

FOSTER, Lila. Filmes domésticos: uma abordagem a partir do acervo da Cinema- 
teca Brasileira. Dissertação (Mestrado). Universidade Federal de São Carlos, São Carlos, 2010.

FREIRE, Rafael de Luna. Um breve histórico do Laboratório Universitário de Preservação Audiovisual (LUPA-UFF). Catálogo CineOP 2018. Belo Horizonte: Universo Produções, 2018.

FUTEMMA, Olga. Rastro de perícia, método e intuição: descrição do arquivo Paulo Emílio Salles Gomes. 2006. Dissertação (Mestrado). Universidade de São Paulo, São Paulo, 2006.

GOMES, Paulo Emílio Sales. Uma situação colonial? São Paulo: Companhia das Letras, 2016.

KAUFMAN, Peter. Towards a New Audiovisual Think Tank for Audiovisual Archivists and Cultural Heritage Professionals. Intelligent Television and MIT. 2018.

MATTOS, Francisco. A representação por palavras do conteúdo de imagens em movimento: uma perspectiva documentária. 2002. Dissertação (Mestrado). Universidade de São Paulo, São Paulo, 2002.

NORONHA, Jurandyr. Indicações para a organização de uma filmoteca brasileira. A Scena Muda, n. 28, 1948, p.8-9-32-33.

QUENTAL, José. A preservação cinematográfica no Brasil e a construção de uma cinemateca na Belacap: a Cinemateca do Museu de Arte Moderna do Rio de Janeiro. Dissertação (Mestrado). Universidade Federal Fluminense, Niterói, 2010. RODRIGUES, Luciana. A formação em audiovisual e cinema e a preservação - uma relação delicada. HEFFNER, H; D’ANGELO, Raquel H; D'ANGELO, Fernanda H. (orgs.). Reflexões sobre a preservação audiovisual 20 I6-20 I5: I0 anos da CineOP. Ouro Preto: Universo, 2015, p. I78-I84.

SILVA, Luiz Antonio Santana. Abordagens do documento audiovisual no campo teórico da arquivologia. Dissertação (Mestrado). Universidade Estadual Paulista, São Paulo, 2013.

SOUZA, Carlos Roberto de. A cinemateca brasileira e a preservação de filmes no Brasil. Tese (Doutorado). Universidade de São Paulo, São Paulo, 2009.

VIEIRA, João Luiz. Dilemas e desafios da formação em preservação. HEFFNER, H; D'ANGELO, Raquel H; D’ANGELO, Fernanda H. (orgs.). Reflexões sobre a preservação audiovisual 2016-2015: 10 anos da CineOP. Ouro Preto: Universo, 20I5, p.|89-19I.

VIEIRA, Thiago. Os documentos especiais à luz da arquivologia contemporânea: uma análise a partir das instituições arquivística públicas da cidade do Rio de Janeiro. Dissertação (Mestrado). Universidade Federal do Estado do Rio de Janeiro, Rio de Janeiro, 2014.

\section{Websites}

Ancine. Plano de Diretrizes e Metas para o Audiovisual. Disponível em: <https:// www.ancine.gov.br/pt-br/plano-de-diretrizes-e-metas>.Acesso em: 2 nov. 2018. ABPA. Cartas de Ouro Preto (2012 e 20I3). Disponível em: <http://www.abpreservacaoaudiovisual.org/site/publicacoes/manuais/22-cartas-de-ouro-preto. html>. Acesso em: 30 out. 2018.

Estatuto (2012). Disponível em: <http://www.abpreservacaoaudiovisual.org/site/abpa/estatuto.html>. Acesso em: 30 out. 2018.

Missão. Disponível em: <http://www.abpreservacaoaudiovisual.org/ site/abpa/missao.html>.Acesso em: 30 out. 2018.

BRASIL. Constituição da República Federativa do Brasil. 1988. Disponível em: <http://www.planalto.gov.br/ccivil_03/Constituicao/Constituicao.htm>. Acesso em: 25 out. 2018. 
BRASIL. Medida Provisória $\mathrm{n}^{\circ}$ 850, de 2018. Disponível em: <http://pesquisa. in.gov.br/imprensa/jsp/visualiza/index.jsp?data=I I/09/20 I 8\&jornal=5 I5\&pagi na $=4>$. Acesso em: 25 out. 2018.

BRASIL. Ministério da Educação. Conselho Nacional de Educação. Resolução n I0, de 27 de junho de 2006. Diário Oficial da União, 7 jul. 2006. Seção I, p.29-30. Disponível em: <http://pesquisa.in.gov.br/imprensa/jsp/visualiza/index.jsp?data $=0$ 7/07/2006\&jornal= I \&pagina=29\&totalArquivos=|44>. Acesso em: 25 out. 2018. BRASIL. Presidência da República. Casa Civil. Lei Nº 6.546, de 4 de julho de 1978. Disponível em: <http://www.planalto.gov.br/ccivil_03/LEIS/L7287.htm>. Acesso em: 3 out. 2018.

BRASIL. Presidência da República. Casa Civil. Lei № 7.287, de 18 de dezembro de 1984. Disponível em: <http://www.planalto.gov.br/ccivil_03/LEIS/L7287.htm>. Acesso em: 3 out. 2018.

CTDAISM/CONARQ. Disponível em: <http://conarq.arquivonacional.gov.br/ ctdaism.html>.Acesso em: I5 out. 2018.

Cinemateca Brasileira. História. Disponível em: <http://cinemateca.gov.br/ pagina/a-cinemateca-historia>.Acesso em: 30 set. 2018.

. Relatórios institucionais. Disponível em: <http://www.cinemateca.org. br/pagina/a-cinemateca-institucional>.Acesso em: 2 nov. 2018.

Classificação Brasileira de Ocupações (CBO) do Ministério do Trabalho. Disponível em: <http://trabalho.gov.br/servicos-do-ministerio/servicos-do-trabalho/

para-o-trabalhador/classificacao-brasileira-de-ocupacoes-cbo/solicitacao-de-inclusao-de-codigo-da-cbo>.Acesso em: 25 out. 2018.

FIAF. Disponível em: <https://www.fiafnet.org/pages/History/FIAF-Timeline. html>.Acesso em: 5 out. 2018.

FSA. Disponível em: <https://fsa.ancine.gov.br/resultados/investimentos/valores-investidos>.Acesso em: 15 nov. 2018.

HEFFNER, Hernani. Preservação. Contracampo Edição 34. Disponível em: <http://www.contracampo.com.br/34/questoesgerais.htm>. Acesso em: 3 out. 2018.

MATUSZEWSKI, Bolesław. Uma nova fonte histórica. Contracampo Edição 34. Disponível em: <http://www.contracampo.com.br/34/matuszewski.htm>. Acesso em: 30 set. 2018.

Michaelis. Disponível em: <https://michaelis.uol.com.br>. Acesso em: 30 out. 2018.

PNPA. Disponível em: <http://www.abpreservacaoaudiovisual.org/site/abpa/plano-nacional-de-preservacao.html>. Acesso em: I 5 nov. 20 I8.

Política de Patrimônio Cultural Material do Iphan. Disponível em:<http://portal. iphan.gov.br/pagina/detalhes/I837>. Acesso em: 10 out. 2018.

SAKAMOTO, Leonardo. Incêndio do Museu Nacional não é tragédia, mas fruto de um projeto de país. Disponível em: <https://blogdosakamoto.blogosfera.uol. com.br/20I8/09/03/incendio-do-museu-nacional-nao-e-tragedia-mas-fruto-de-um-projeto-de-pais>. Acesso em: 28 set. 2018.

SECRJ. Programas Setoriais do Audiovisual 20I5. Disponível em: <http://www. cultura.rj.gov.br/uploads/files/programa_proposta_pelos_comites_gestores_ do_audiovisual.pdf>.Acesso em: 2 nov. 2018.

Unesco. Recommendation for the Safeguarding and Preservation of Moving Images. General Conference in Belgrade. 1980. Disponível em: < http://www.unesco. org/new/en/unesco/resources/publications>.Acesso em: 2 nov. 2018.

Universo. CineOP - I ${ }^{\text {a }}$ Mostra de Cinema de Ouro Preto. Disponível em: <http:// cineop.com.br/a-mostra/edicoes-anteriores/I3>.Acesso em: 5 out. 2018. 